\title{
ABEL POSSE: ENTRE EUROPA Y AMÉRICA
}

\author{
Maria Rita Corticelli
}

\begin{abstract}
RESUMEN
El artículo describe las características de la recíproca influencia entre la cultura europea y la americana en la novela Los perros del paraíso del escritor argentino Abel Posse. En particular, en el estudio se analiza la relación entre la filosofía europea y americana en la composición de esta novela.
\end{abstract}

\begin{abstract}
The article describes the characteristic of the reciprocal influence between European and American culture in the novel Los perros del paraíso by the Argentinean writer Abel Posse. In detail, it provides an analysis of the relationship between European and American philosophy in the composition of the novel.
\end{abstract}

Desde Machiavelo hasta algunas recientes teorizaciones acerca de la hibridización o la heterogeneidad cultural, la alteridad siempre ha sido tomada como centro de referencia para diversas formulaciones de poder, tanto en lo político como en el campo de la interacción cultural. A pesar de que en todas haya un esfuerzo más o menos logrado por dar una respuesta a esta confrontación, en ellas siempre encontraremos un límite problemático debido a que se elaboran inevitablemente desde una perspectiva privilegiada. Ninguna, ni las más contemporáneas de Edward Said (1975, 1979 y 1993) o de Robert Young (1995), por ejemplo, ha de tener la flexibilidad ideal para, en particular, apropiarse y moldear patrimonios culturales diversos, sean estos el del conquistador y el del conquistado u otros, o para, en general, crear una distinta relación con el otro que supere concepciones tradicionales del poder que imponen la supremacía exclusiva de una cultura sobre otra, de un grupo social sobre otro. Tanto en lo político como en lo cultural, sería ingenuo pedir que estas formulaciones renunciaran a la posición privilegiada desde la que se enuncian como si pudieran obtener mayor flexibilidad solo a partir de su propia coherencia discursiva. Siempre han de ser formulaciones, y me parece más justo reconocer que su límite viene marcado desde "fuera", desde la propia experiencia histórica, que es en donde se dirimen las cuestiones del poder y del diálogo entre grupos en conflicto.

Justamente a pesar de ese límite - o debido a él: para vencerlo y asimilarlo - no cesan los intentos de imaginar de otro modo la relación con la alteridad, aun cuando ese intento en algunos casos pueda implicar subsumir o anular la existencia del otro. En la cultura y la literatura latinoamericanas, estos intentos a veces son parte de reflexiones más generales y abstractas 
acerca de "lo americano", "lo nuestro", "la identidad", etc; a veces se mezclan con reflexiones acerca de lo autóctono versus lo cosmopolita, lo nacional versus lo foráneo, lo tradicional versus lo moderno, lo americano versus lo europeo, o más específicamente, acerca de la interacción de diversas tradiciones étnico-culturales que operan en cada área del continente. Estos intentos han nutrido permanentemente no solo la literatura "de creación" sino también la ensayística y el pensamiento latinoamericanos, hasta producir términos (conceptos, nociones o metáforas-conceptos) como lo real maravilloso, lo sincrético y lo híbrido ${ }^{1}$.

Un propósito central de mi investigación ha sido examinar las percepciones de la heterogeneidad cultural y social y la narrativización del otro como elementos claves de la construcción de la identidad en la novela hispanoamericana. Como he señalado, ese examen demanda una consideración de la concepción de poder que, implícita o explícitamente, los textos figuran, tanto en el ámbito de la política como en las interacciones culturales.

El breve recorrido que haré a través de la historia del pensamiento moderno responde entonces a la necesidad de delinear algunas perspectivas con las que Abel Posse ha reflexionado acerca de esa referencialidad problemática que el otro constituye ${ }^{2}$.

En la concepción de la política moderna diversos pensadores han planteado la cuestión de la formación del estado y de la relación de los súbditos/ciudadanos con quien ejerce el poder, sea este representante de un sistema absolutista o elegido por una más amplia base democrática. Para mi reflexión me interesa enfatizar que en el siglo XVIII, en particular en el pensamiento de Rousseau, esta relación se vincula a una concepción más articulada del proceso evolutivo del hombre desde un estadio hipotético de naturaleza a una etapa de convivencia en una sociedad que incluye necesariamente la pérdida irremediable de esta misma condición originaria. La Revolución Francesa traslada luego el principio de igualdad de este contexto de crítica de la sociedad moderna a la afirmación de derechos individuales, y transforma al individuo de súbdito en ciudadano.

Este cambio, tan radical en la época que se produjo, se debe a una serie de innovaciones previas no sólo en filosofía sino en la economía europea y en la importancia que asume una nueva clase, la burguesía, que logra imponer sus valores y que busca una participación directa en la vida política de las naciones. Es necesario precisar que en este largo período ya se había conformado y desarrollado el pensamiento liberal, cuyo punto de arranque hay que buscarlo en el filósofo inglés John Locke: las ideas políticas de Locke habían tenido una gran influencia en Francia, a través de Voltaire, y habían transmitido al continente europeo toda la energía de la fuerte burguesía inglesa y holandesa. En este contexto general la relación entre la historia y la filosofía se hacía cada vez más estrecha. John Locke había vivido una época de plena expansión colonial: un mundo más ancho demandaba maneras de pensar e interpretaciones más abarcantes. En particular, el problema de la propiedad privada se trasladaba de un nivel local a un plano internacional.

En este contexto, la estrategia narrativa de Posse se expresa en promover un diálogo constructivo entre la cultura europea y las tradiciones americanas siguiendo las huellas de Alejo Carpentier y, sobre todo, de José Lezama Lima. Rompiendo las barreras espacio-temporales impuestas por la filosofía de la historia hegeliana, Posse define la cultura como un flujo, un movimiento constante y no como una entidad monolítica y excluyente. El libre uso de los mitos occidentales y americanos permite al escritor encontrar una relación recíproca entre ambas vertientes culturales y colocar el debate acerca de la identidad latinoamericana en una nueva perspectiva que refleje un nuevo balance de poder entre los dos polos. 
Esta estrategia se desplaza en dos etapas: en la primera, el escritor se confronta directamente con las mayores corrientes filosóficas europeas; en la segunda, reelabora los aportes de pensadores americanos como Alejo Carpentier y José Lezama Lima. En ambas etapas, tal estrategia tiene como condición la aceptación de los aportes de los filósofos europeos y pensadores americanos, y luego como motivación, la superación de sus posiciones para proponer una visión original de la relación entre la cultura occidental y el otro, sea este europeo o autóctono de América.

En Los perros del paraíso el escritor se confronta directamente con la filosofía hegeliana y su influencia en la política expansionista del siglo pasado. Según Hegel, en las Lecciones sobre la filosofía de la historia universal (1837), el otro americano, empezando por su medioambiente geográfico, es "inmaduro" y demasiado reciente para poder desarrollar una cultura propia, demasiado pobre de ideas para poder participar directamente en el flujo de la historia. Dice el filósofo:

Sin embargo, el mar de las islas, que se extiende entre América del Sur y Asia, revela cierta inmaturidad por lo que lo toca también a su origen. La mayor parte de las islas se asientan sobre corales y están hechas de modo que más bien parecen cubrimiento de rocas surgidas recientemente de las profundidades marinas y ostentan el carácter de algo nacido hace poco tiempo (24).

Y sigue:

(...) El mar Mediterráneo es elemento de unión de esas tres partes del mundo, y ello lo convierte en el centro de toda la historia universal. El Mediterráneo con sus muchos golfos y bahías, no es un Océano, que empuja hacia lo indeterminado y con el cual el hombre sólo mantiene una relación negativa. El Mediterráneo sólo invita al hombre a utilizarlo. El Mediterráneo es el eje de la historia universal. Todos los grandes Estados de la historia antigua se encuentran en torno de este ombligo de la tierra. Aquí está Grecia, punto luminoso de la historia (38-9).

Posse polemiza con esta visión de la filosofía hegeliana remitiéndose a las mismas raíces culturales occidentales usadas por el filósofo alemán. Hegel veía en la teoría de los opuestos formulada por Heráclito el origen de su filosofía dialéctica, pero muchos críticos contemporáneos han notado que la recuperación de Heráclito por parte de Hegel sufre de una limitación: el filósofo alemán "hegeliza" a Heráclito atribuyendo al filósofo griego conceptos contemporáneos como el de progreso y síntesis, y olvidándose por completo del lado "irracional" de la filosofía heracliteana que basa su interpretación de la realidad en la combinación de cuatro elementos naturales: aire, agua, fuego, tierra.

Posse, rompiendo los límites impuestos por Hegel, reinterpreta a Heráclito estableciendo una conexión entre la teoría de los elementos del filósofo griego y la del Popul Vuh ${ }^{3}$ que ve en los mismos elementos el origen de la realidad. Este puente entre la filosofía occidental y la mitología del nuevo mundo abre nuevas posibilidades de fusión entre las dos culturas: superar a Hegel significa superar su concepción de la filosofía de la historia y crear una historia alternativa que incluya al otro no europeo usando el mismo patrimonio cultural europeo.

El resultado último de este esfuerzo intelectual de sincretismo cultural es la creación de una nueva definición de cultura que tome en cuenta el aporte de ambas culturas. Para Posse la cultura no es una entidad "congelada" sino un momento de refundición en el que todos los 
elementos históricos concurren para dar vida a una nueva visión que rehúsa una interpretación tradicional de la historia y de la cultura misma.

Si confrontarse con la dialéctica hegeliana puede haber sido cosa relativamente fácil para el escritor argentino, la figura del segundo filósofo alemán es sumamente compleja. Nietzsche es el filósofo que muestra la otra cara de la medalla presentada por Hegel: la crítica nietzscheana a la cultura occidental lo pone al margen de la historia de la filosofía misma. Personaje de Los perros del paraíso, su constante aparición en la narración de las etapas más difíciles de la conquista, atestigua la estrategia del escritor argentino: la cultura occidental no puede verse como un bloque único; como ha pasado con los aportes americanos, en ella misma hay voces que han sido silenciadas para dejar espacio a las voces del poder. En constante crítica a la civilización occidental y a la concepción de la historia ofrecida por las filosofías a él contemporáneas, en particular al liberalismo y al marxismo, Nietzsche constituye un momento importante dentro de la reevaluación del patrimonio cultural europeo.

En su Nacimiento de la tragedia el filósofo alemán menciona la importancia del mito en el desarrollo del conocimiento. Dice Nietzsche (1982):

\begin{abstract}
Guardiamo ora a Socrate, con la fiaccola di questo pensiero: egli ci appare come il primo, che seppe con la guida di quell'instinto della scienza non solo vivere, am anche - e que é ben piú morire; e perció l'immagine del Socrate morente, come dell'uomo sottratto dal sapere e dai ragionamenti alla paura della morte, é il blasone che sull aporta d'ingresso della scienza ricorda ad ognuno la destinazione di essa, quella cioé di far apparire l'esistenza intelligibile e quindi giustificata: al quale scopo certamente, se non giungono i ragionamenti, deve alla fine servire anche il mito che io ho poc'anzi designato addirittura come conseguenza necessaria, anzi come scopo della scienza.
\end{abstract}

El mito asume un rol fundamental dentro de la concepción de la historia ofrecida por Nietzsche, y Posse enriquece su obra con este importante aporte de la filosofía occidental. Para Nietzsche, como para el escritor argentino, la historia nunca puede ser una historia objetiva sino siempre un esfuerzo de la fantasía, no una recopilación de datos que remiten siempre al pasado sino un mirada hacia el futuro.

Esta concepción de la historia nos lleva directamente a la idea que Nietzsche tiene de las relaciones entre los hombres en la sociedad misma. Rechazando la idea de igualdad propuesta por el marxismo y el socialismo, Nietzsche propone la "voluntad de poder". Para él, esta doctrina explica el carácter de toda la realidad. Los hombres, como los animales y todos los seres vivos responden a esta voluntad que excluye toda posibilidad de una relación de paridad entre ellos: es la voluntad de superarse que dirige todos los aspectos constituyentes de la realidad misma. Dejando de lado las varias interpretaciones que se han dado de la filosofía nietzscheana, esta voluntad de poder tiene un notable límite: si el hombre puede superar todo, entonces un día, gracias a su voluntad de poder, podrá superar su condiciones de desigualdad. Según Nietzsche, creación es voluntad de poder y gracias a esta todo puede ser superado, pero, ¿hasta qué extremo el filósofo alemán lleva su filosofía de la voluntad de poder? ¿Puede todo ser superado al infinito? ¿Cuánto se atreve a cancelar Occidente para dar espacio a la alteridad? Leo Strauss (1987: 846) señala que:

Nietzsche believes in a hierarchical society, in the superiority of men over women, and in the necessity for suffering. But if the will to power is all, and if all is in principle possible, why 
should not and why will not the difference between the sexes or the rank differences between men be abolished?

Leo Strauss subraya una aporía muy grande en la filosofía de Nietzsche que ha transformado al filósofo de la crítica a Occidente en el filósofo que, a través de las ideas de voluntad de poder y de superhombre, ha inspirado el nazismo y el fascismo.

Según Nietzsche, la igualdad se identifica con la masificación del hombre y, para evitar que su filosofía se transforme en una utopía para el futuro, introduce el concepto del eterno retorno. Con este concepto, intenta resolver la contradicción entre la completa "deconstrucción" de la cultura occidental y su idea de la jerarquía. Dice Leo Strauss (1987: 846):

(...) the return of all things guarantees the existence of low things and therefore of things which cannot be overcome by the will to power. By willing the eternal return the will reaches its highest peak: it overcomes itself but survives in the total affirmation of all things. Through the total affirmation of all things man can cease to be man and becomes superman.

Todo lo que pasa en el flujo de la historia está destinado a volver varias veces y a repetirse sin cambios, y si Nietzsche cree en una sociedad jerárquica, estas diferencias tienen que mantenerse idénticas dentro de la expresión de la voluntad de poder. Si su visión de la historia se destaca por ser una crítica a la historia lineal occidental, el mismo Nietzsche no puede llevar su propia percepción de la historia hasta las extremas consecuencias. La aparente libertad dada a la expresión de la voluntad de los seres humanos termina atrapada dentro de la idea del eterno retorno: todavía una situación sin salida, un movimiento que encuentra su justificación en el movimiento mismo, pero que no aporta ningún cambio. Su filosofía, que se ha atrevido a imaginar un futuro libre de las cadenas del pasado, de repente parece tener miedo de volar y necesita del eterno retorno para parar el mismo flujo que él ha puesto en movimiento.

Lo que me interesa destacar es que la idea del eterno retorno que debería de sugerir un movimiento hacia el cambio, representa el momento en el que el filósofo alemán reafirma la existencia de una jerarquía en la constitución misma de la realidad: el eterno retorno significa la repetición eterna de los mismos sufrimientos, de los mismos deseos, de las mismas injusticias que rigen las relaciones entre los hombres. Limitando su filosofía a un eterno ejercicio de la misma voluntad de poder, Nietzsche limita su movimiento acercándose más a Hegel y excluyendo al otro de su interpretación de la realidad.

Que Nietzsche crea en una jerarquía está claro en la división de los tipos de historias que él plantea: una historia Monumental, una Anticuaria y una Crítica. La que más interesa para este estudio es la historia Anticuaria que prevé una sana relación con la tradición y que el filósofo indica como muy saludable para los pueblos "less gifted" porque los salva de un "restless and unproductive cosmopolitanism" (Strauss 1987:831). Los ecos de Rousseau (1915, 1964, 1982) resuenan en la obra del filósofo que más critica la civilización occidental: otra vez se idealiza a los pueblos primitivos, otra vez el estado natural se define por estar en contraste con la corrupta sociedad occidental. ¿Cuál es, entonces, la postura de Nietzsche con respecto al poder que la misma civilización occidental ejerce sobre los pueblos menos desarrollados? No hay una clara respuesta a esta pregunta; su extremo interés por la filosofía oriental, por ejemplo, demuestra que el filósofo ha leído y ha usado un patrimonio cultural no occidental. 
Los perros del paraíso representa un esfuerzo para reinventar la historia de la conquista de América dentro de una perspectiva en la que el pasado, el presente y el futuro se cruzan: todos los personajes que aparecen son históricos, pero con un procedimiento nietzscheano, Posse renuncia a la protección de la historiografía oficial y construye su propia versión. Como el filósofo nietzscheano, el intelectual americano propuesto por Posse tiene que captar la dimensión oracular del pasado para forjar el futuro, porque a él

Incombe [...] rendere visibile, pensabile, comprensibile, maneggiabile tutto ció che finora é accaduto ed é stato stimato, di abbreviare ogni cosa troppo lunga, ansi "il tempo" stesso, e di sopraffare tutto il passato; [...] Il loro "conoscere" é creare, il loro creare é una legislazione, la loro volontá di veritá é - volontá di potenza (Al di lá del bene e del male,146).

A pesar del uso que Posse hace de Nietzsche, su visión de América le impide aceptar todos los matices del pensamiento del filósofo alemán. La fase "destructiva" de la filosofía nietzscheana permite al escritor argentino llevar a América el instinto de rebelión contra una cultura muerta, que poco puede proponer al nuevo continente, y que necesita ser reelaborada y reconstruida para que pueda ser de alguna utilidad en la realidad americana.

Nietzsche propone una visión de la historia que rompe con las reglas espacio-temporales impuestas por la filosofía de la historia hegeliana y, por primera vez, se atreve a superar los límites de la cultura occidental incluyendo en su obra aportes de otras culturas, la oriental en particular. Pero, ¿Nietzsche consigue de verdad superar la filosofía occidental, u ofrece la interpretación de la filosofía oriental que más satisface la mentalidad occidental? Después de su fase "deconstructiva" de la historia y de la cultura, Nietzsche propone una fase "constructiva" que tiene su cumbre en la idea del eterno retorno.

Posse sigue al filósofo alemán sólo hasta donde su filosofía puede contribuir a la construcción de una nueva concepción de la historia para América. Como el filósofo alemán, el escritor se atreve a "deconstruir" la historia mundial para "construir" un discurso fundacional de América. Pero, al mismo tiempo, el escritor argentino sabe alejarse del filósofo alemán cuando las ideas del eterno retorno y de la voluntad de poder llegan a "congelar" otra vez la historia en una concepción dinámica de poder que no tiene salida: seguir a Nietzsche hasta sus extremas consecuencias, significaría aceptar una jerarquía y obligar a América a repetir para siempre su posición subordinada con respecto a Europa y se perdería el planteamiento de una relación de paridad entre las dos culturas.

En América, Alejo Carpentier y José Lezama Lima representan los puntos de partida clave para la reflexión de Posse sobre América. Carpentier es el padre reconocido de lo real maravilloso, pero el elemento que más le interesa a Posse es la doble lectura que algunas obras de Carpentier ofrecen al lector. En particular en El reino de este mundo, la confrontación entre el mundo racional europeo y la dimensión mágico religiosa de los esclavos africanos sugiere al lector la coexistencia de dos posibles interpretaciones de la misma realidad (MocegaGonzález 1975, Velayo Zurdo 1990).

Posse hereda la sensibilidad del escritor cubano por el mito y por el sincretismo cultural, pero supera la visión dicotómica de Carpentier. El discurso sobre la identidad ofrecido por el escritor cubano no lleva hasta los límites extremos el sincretismo que se encuentra en sus novelas. La coexistencia de la cultura europea y de la cultura africana no constituye por sí misma una prueba de sincretismo: las dos culturas proceden paralelas, sin nunca encontrar un terreno 
común. Además, el escritor cubano da una interpretación causa-efecto de la historia y las cíclicas metamorfosis de Ti Noel dan la impresión de que la historia se repite indefinidamente.

Pero es en el barroco americano de Lezama Lima que Posse encuentra un terreno fértil para desarrollar su propia idea de sincretismo. La originalidad del discurso cultural formulado por Lezama Lima está en la propuesta de un uso libre de la cultura: más específicamente, el profundo conocimiento que el escritor cubano tiene de la cultura europea y de la cultura autóctona americana, desemboca en una original visión de América y de su relación con el viejo continente.

Por otro lado, en el ensayo "La cantidad hechizada" 4, de Lezama Lima, la historia se figura como una red de relaciones que se desarrollan en un espacio-tiempo que solo la imaginación puede crear. La historia, entonces, no es una serie de eventos sino un "devenir" histórico. El concepto de era imaginaria es sumamente importante para la participación de América en la cultura occidental. Una era imaginaria no coincide con una cultura específica, sino que es un momento que sobresale dentro de una tradición cultural más amplia. En este sentido, América puede participar completamente en el patrimonio cultural occidental y compartir cualquier tradición cultural "sin compromiso alguno". Esta libertad le permite a Posse, igualmente sin compromiso, viajar a través de las culturas para formular su propio discurso de la identidad cultural.

Pero el uso de la imaginación no puede prescindir de las fuentes concretas de inspiración: el discurso sobre el arte que inaugura Lezama Lima obliga a revisar una serie de juicios ya establecidos sobre el arte europeo y a mirar al arte americano como a un fenómeno nuevo que sigue reglas distintas. Es en La expresión americana que el escritor cubano presenta el barroco como el arte de América, identificando en la Indiatide la forma artística sincrética entre Europa y América. Especialmente, lo visual se convierte en un terreno fértil para la creación de un arte propiamente americano: considerado una degeneración del Renacimiento, el barroco se traslada a América y se transforma en la forma de arte que más expresa la riqueza del nuevo continente.

Inspirado por la arquitectura autóctona de América, el barroco americano llega a ser una forma de arte completa que expresa el sincretismo de un pueblo. El antropólogo peruano Ramón Mujica Pinilla señala que:

El barroco tiene su gran virtud en su poder asimilista. [...] En el siglo XVII los misioneros franciscanos y jesuitas escribían mitos quechuas para catequizar porque en este siglo, a raíz del barroco, hay un nuevo interés por la mitología clásica, pero para ellos el Perú precolombino formaba parte de este mundo clásico. [...] El barroco es otra definición del arte: la obsesión del artista renacentista es la perspectiva, uno ingresa al cuadro; en el arte barroco es todo lo contrario, la pintura o la escultura se convierte en una especie de ventana abierta a un mundo luminoso, y es a través de esta ventana que se representa el arquetipo que está en el cielo. La imagen del santo es un reflejo del santo que está en el cielo, de allí los sobredorados como parte del mundo sacral. De esta ventana el santo ingresa al mundo temporal humano; por eso todos los grandes milagros de los santos barrocos tienen que ver con las imágenes que se mueven, hablan, cobran vida. La imagen es el nexo entre el arquetipo divino y su forma temporal que tiene que ver con un curso determinado de la imaginación 5 .

He citado en extenso a Mujica Pinilla, a propósito del arte barroco en América, porque su descripción nos remite inmediatamente a la idea de imagen que Lezama Lima desarrolla en 
sus ensayos y que le permite vivir dinámicamente la experiencia de la creación. Pero el dato fundamental del aporte antropológico para una definición del barroco americano es que el sincretismo no es meramente visual, sino que pertenece a la historia real de los pueblos: el caso de Perú es un ejemplo muy concreto. El arte mural que se encuentra en todo el país, y especialmente en todas las zonas andinas alrededor del Cuzco, atestigua cuánto el sincretismo ha sido y sigue siendo una experiencia viva y dinámica en la sociedad. En Las eras imaginarias de Lezama Lima la historia es una red de relaciones que se desarrollan en un espacio-tiempo que solo la imaginación puede crear. La historia, entonces, no es una serie de eventos sino un "devenir" histórico. Una era imaginaria no coincide con una cultura específica, sino es un momento que sobresale dentro de una tradición cultural más amplia. En este sentido, América puede participar completamente en el patrimonio cultural occidental y compartir cualquier tradición cultural "sin compromiso alguno". Una libertad que permite a Posse, igualmente sin compromiso, viajar a través de las culturas para formular su propio discurso de la identidad cultural.

Pero el uso de la imaginación no puede prescindir de las fuentes concretas de inspiración: el discurso sobre el arte que inaugura Lezama Lima obliga a revisar una serie de juicios ya establecidos sobre el arte europeo y a mirar el arte americano como un fenómeno nuevo que sigue reglas distintas. En La expresión americana el escritor cubano presenta el barroco como el arte de América, identificando en la Indiatide la forma artística sincrética entre Europa y América. Lo visual se convierte en un terreno fértil para la creación de un arte propiamente americano: considerado una degeneración del Renacimiento, el barroco se traslada a América y se transforma en la forma de arte que más expresa la riqueza del nuevo continente. Inspirado por la arquitectura autóctona de América, el barroco americano llega a ser una forma de arte completa que expresa los valores colectivos de un pueblo.

Posse aprende de Lezama Lima su propia definición de cultura. Su tentativa de participar en la creación de una cultura latinoamericana tiene en cuenta la posibilidad de una "igualdad" entre Europa y América. Pero Posse supera la visión lezamiana: el escritor argentino compara, no un proceso artístico o histórico, sino seres humanos por su ser "marginales", sea en Europa o en América Latina. Sus personajes de ambos continentes tienen en común el sentirse excluidos dentro de su mismo mundo. Dice el escritor argentino:

Yo he querido mostrar también que estos europeos que venían, tenían nombres como Nietzsche, como Svedenborg, que era tan americanos como los indios, en cuanto marginales, a hombres del pensamiento de reacción contra la noción judeo-cristiana. Forma parte del drama más íntimo del libro, ese juego (Spiller 1989: 111).

Si la teoría de Lezama Lima silencia cada consideración de tipo social y "[...] art is a moment in which every contrast finds a solution [...]" (Corticelli 1196: 100-8), Posse no crea otra imago congelada como puede volverse la del Indio Kondory lezamiano.

La labor intelectual de Posse no se limita a la reelaboración de fuentes literarias o de corrientes de pensamiento; el escritor argentino asume plenamente el rol de filósofo y escritor de América y, haciendo eso, su obra de ficción, se compromete a transmitir el patrimonio cultural que define la identidad de un pueblo, el americano que finalmente participa plenamente en el flujo de la historia mundial. 


\section{Notas}

1. A pesar de que este estudio privilegia la relación del escritor con la política, la filosofía política y, a veces, con la historia concreta, no se tiene que olvidar que el tema de "lo híbrido" dentro de la tradición cultural y literaria en América Latina ha sido tratado por críticos de fundamental referencia como Ángel Rama en Transculturación narrativa en América Latina, Siglo XXI Ed., México D.F., 1982; Antonio Cornejo Polar en Escribir en el aire: ensayo sobre la heterogeneidad socio-cultural en las literaturas andinas, Ed. Horizonte, Lima, 1994; y Néstor García Canclini en Las culturas populares en el capitalismo, Ed. Nueva Imagen, México D.F., 1982, y en Culturas híbridas: estrategias para entrar y salir de la modernidad, Ed. Grijalbo, México, 1989.

2. Usaré aquí la expresión "el otro" no en el sentido específico de "el Otro", resaltado por la mayúscula y recurrente en ciertas teorías de la subjetividad para referirse, por ejemplo, a lo que en Lacan se denomina el orden simbólico (la norma, la ley del padre, etc.) ante el cual el individuo se constituye como subjeto. La expresión tendrá aquí el sentido más lato de "alteridad" u "otredad", es decir, aquello que, en la cultura y la política, es distinto de un personaje, un narrador o un autor. Ese "otro" y ese ser distinto se irán precisando en el análisis y podrán ser percibidos más específicamente en cada contexto de mi exposición.

3. El mito de la creación del hombre que encontramos en el Popul Vuh tiene muchos puntos en común con las teorías pre-socráticas, en ello hay distintas tentativas de construir el hombre y los elementos primarios que concurren utilizados por los dioses son, justamente, aire, agua, fuego y tierra, los mismos que encontramos en la filosofía pre-socrática. Rodrigo Beteta, Virgilio. Los dos brujitos Mayas: el cuento novela de la antigüedad americana, San Salvador, Ministerio de Educación, 1974.

4. Lezama Lima, José. "La cantidad hechizada", Obras Completas, Ed. Aguilar, México, 1977. En este ensayo Lezama Lima desarrolla este concepto remitiéndose a ejemplos de la historia del arte. Dice el escritor:"Veamos a Van Gogh agitado por las espirales del amarillo en un fondo donde se extiende la aceptación del azul. Una cabellera arde en un amarillo devorada lentamente por un azul bituminoso. Le obsesiona lo estelar fijado en el cóncavo. Sus tormentos tal vez cesarían si su imaginación se desplazase hacia una era imaginaria, como la asiria, donde lo estelar predomina. Sus espirales se calmarían en un despliegue de cacería, su oro en las tiaras de las consagraciones, sus jardines en la fuga de azoteas donde se persigue a la estrella (799).

5. Esta cita se encuentra en una entrevista inédita que el autor de este estudio hizo al antropólogo peruano Ramón Mujica Pinilla en Lima el 3 de septiembre de 1998.

\section{Bibliografía}

Aínsa, Fernando. 1991. "La nueva novela histórica latinoamericana". Plural. 240: 82-5.

Almazan, M.I., Ranucci, E.G. 1991. "Los perros del paraíso, de Abel Posse: una ruptura flagrante del orden espacio-temporal establecido". Literatura como intertextualidad. IX Simposio Internacional de Literatura. Asunción, Paraguay,.

Argan, Carlo Giulio. 1988. Storia dell'arte italiana. Firenze: Ed. Sansoni.

Capizzi, Antonio. 1979. "Tracce di una polemica sulla scrittura in Eraclito e Parmenide". Giornale critico della filosofia italiana. Vol. 10, Anno LVIII.

Carpentier, Alejo. 1987. El reino de este mundo. La Habana: Ed. Letras Cubanas. 
1985. Los pasos perdidos. Madrid: Ed. Cátedra.

1985. El siglo de las luces. Madrid: Ed. Cátedra.

Cornejo Polar, Antonio. 1994. Escribir en el aire: ensayo sobre la heterogeneidad sociocultural en las literaturas andinas. Ed. Horizonte.

Corticelli, Maria Rita. 1996. "La vida exagerada de Martín Romaña: Towards cultural syncretism". Iberroromania. 44, Tübingen, 100-8.

Cousineau, Robert H. 1991. Zarathustra and the Ethical Ideal. Amsterdam: John Benjamins Publishing Company.

García Pinto, Magdalena. 1989. "Entrevista con Abel Posse". Revista Iberoamericana. 55 (146/147): 493-506.

Hatab, Lawrence J. 1995. A Nietzschean Defense of Democracy. Chicago: Court Publishing Company.

Hegel, G.W.F. 1952. Lectures on the Philosophy of History. London: Ed. Henry G. Bohn. 1942. Philosophy of Right. Oxford: Ed. Clarendon.

Hyppolite, Jean. 1996. Introduction to Hegel's Philosophy of History. University Press of Florida.

Labriola, Isabella. 1981. "Il fuoco, lo scambio e l'unitá degli opposti." Atti del Simposium Heracliteum. Universitá di Chieti.

Levi-Strauss, Claude. 1968. The Savage Mind. Chicago: Chicago University Press.

Lezama Lima, José. 1993. La expresión americana. México: Fondo de Cultura Económica.

1977. Obras completas. México: Ed. Aguilar

1980. Paradiso. Madrid: Ediciones Cátedra.

Mujica Pinilla, Ramón. 1992. Ángeles apócrifos en la América virreinal. Lima: Fondo de Cultura Económica.

Menton, Seymour. 1992. "Christopher Columbus and the New Historical Novel". Hispania. 75 (4): 930-40, octubre.

Mocega-González, Esther. 1975. La narrativa de Alejo Carpentier: El concepto del tiempo co- 
mo tema fundamental (Ensayo de interpretación y análisis). New York: Ed. E. Torres. Magris, Aldo. 1981. "Il carattere per un uomo, é il suo demone." Atti del Symposium Heracliteum, Universitá di Chieti.

Machiavelli Niccoló. 1972. Il Principe, L’arte della guerra. Club degli Editori, Milano.

1981.Capitoli. Bulzoni, Roma.

Nietzsche, Friedrich. 1927. La nascita della tragedia ovvero Ellenismo e pessimismo. Ed. Monanni, Milano.

1927a. Umano, troppo umano. Un libro per spiriti liberi. Ed. Monanni, Milano.

1927b. La gaia scienza. Ed. Monanni, Milano.

1927c. Al di lá del bene e del male. Ed. Monanni, Milano.,

1927d. La volontá di potenza. Ed. Monanni, Milano.

1959. Cosí parló Zarathustra. Ed. Utet, Torino.

Patiño Correa, Viviana. 1990. "Los perros del paraíso de Abel Posse". Anales de literatura hispanoamericana, n. 19, pp. 175-98.

Pites, Silvia.1993. "Entrevista con Abel Posse". Chasqui, v. XXII (2), Noviembre, pp. 120-8.

Posse, Abel. 1993. Los perros del paraíso. Ed. Plaza y Janes, Barcelona.

1989. Daimón. Ed. Emecé, Buenos Aires.

1971. La boca del tigre. Ed. Emecé, Buenos Aires.

1975. Los bogavantes. Ed. Planeta, Barcelona.

1988. La reina de plata. Ed. Emecé, Buenos Aires.

Rama, Angel.1982. Transculturación narrativa en América Latina. Siglo Veintiuno Ed., México D.F.

Rodríguez Beteta, Virgilio. 1974. Los dos brujitos Mayas: el cuento novela de la antigüedad americana. San Salvador: Ministerio de Educación.

Rodríguez Rodríguez, Alfonso.1992. Deseo, voluntad de potencia y vida. Ed. Universidad del Valle, Colombia.

Rousseau, Jean-Jacques. 1915. The Political Writings of Jean-Jacques Rousseau. C.E. 
Vaughan (ed.) Cambridge University Press, Cambridge.

1964. The First and Second Discourses. Roger D. Masters (ed.), New York.

1982. The social contract. Regnery Gateway (ed,), Chicago.

Russel, Bertrand. 1972. A History of Western Philosophy. Ed. Simon and Schuster, New York.

Said, Edward. 1975. Beginnings. Colombia University Press, New York.

1979. Orientalism. Ed. Vintage Books, New York.

1993. Culture and Imperialism. Ed. Vintage Books, New York.

Senzasono, Luigi. 1981. "Eraclito in Hegel." Atti del Symposium Heracliteum, Universitá di Chieti.

Spiller, Roland. 1989. Conversación con Abel Posse. Iberoamericana, 2/3, 37/38, pp. 106-14.

Stelio, Cro. 1990. The Noble Savage: Allegory of Freedom. Wilfred Laurier University Press.

Strauss, Leo. 1987. History of Political Philosophy. University of Chicago Press, Chicago.

Velayo Zurdo, Oscar. 1990. Historia y utopía en Alejo Carpentier. Ed. Universidad de Salamanca.

Young, Robert. 1995. The Colonial Desire: Hybridity in Theory, Culture and Race. New York: 